\title{
The Interrelationship Between Social Anxiousness and Psychological Defense Mechanisms*
}

\author{
Igor Shelekhov $^{1}$, Elena Grebennikova ${ }^{1}$ \\ ${ }^{1}$ Faculty of psychology \\ Tomsk State Pedagogical University \\ Tomsk, Russia
}

\author{
Olga Marukhina ${ }^{2}$, Elena Berestneva ${ }^{2}$, \\ ${ }^{2}$ Dept. of Optimization Control Systems, \\ National Research Tomsk Polytechnic University \\ Tomsk, Russia
}

\begin{abstract}
The article addresses the problem of social anxiousness of university students through its relationship with psychological defense mechanisms involved in maintaining psychological homeostasis. The article contains the data of the empirical study conducted as part of the comprehensive program of psychosocial support for students who find in conditions of disadaptation. The study shows that the students with increased level of social anxiousness use in critical situations both the less mature mechanisms (projective psychological defense mechanisms) such as repression and regression and the more mature such as psychological projection and compensation using perceptual defense levels with the removal of information from the consciousness as well as the level of restructuring of the information. The choice of psychological defense mechanisms depends on many factors and primarily on personality structure, level of educational attainment, social status, age and sex, which requires further study. A powerful stress or crisis factor, mental disorder or pharmacological deviations can determine the specific set of used psychological defense mechanisms.
\end{abstract}

Keywords-social anxiousness, social anxiety disorders, psychological defense mechanisms, students.

\section{INTRODUCTION}

Students as the most progressive group of youth, are considered as a major state social resource. Social, moral and psychological climate of the society are determined to a large degree by the society moral and intellectual development and professional readiness level. Any transformations of the society primarily become evident in student community. Because of age, psychological and social peculiarities the student body is the most susceptible group of the society and the indicator of positive and negative processes occurring in it $[1,2]$.

Studying at the university is closely related to social interaction and such phenomenon as social anxiousness can have a negative impact on the process of social and emotional adjustment and the quality of life of students. Social anxiousness is a state of emotional discomfort, fear, apprehension and anxiety towards the social situation and assessments given by other people [3, 4].

The research is conducted with financial support from The Russian Foundation for Basic Research, project № 14-06-00026

\section{PSYCHOLOGICAL PROFILE OF STUDENTS}

V. V. Krasnova and A. B. Kholmogorova made up psychological profile of a student with high levels of social anxiousness on the basis of the own studies [5]:

- $\quad$ tends to avoid situations in which the manifestation of social activity and sociability is required. shy and inactive during speeches at seminars and practical trainings. doesn't tend to joint activity and cooperation with the fellow students;

- experiences severe mental stress and discomfort in situations of interaction with unfamiliar people or with people of senior social rank.

- $\quad$ is not able to ask the teacher and fellow students for help. doesn't participate in public events; shy and silent in the student companies;

- experiences serious difficulties when meeting and communicating with the opposite sex;

- sensitive to the opinion of the others about him/herself. In the communication experiences severe anxiety due to possible seeming stupid and uninteresting. Critical remarks inclined to be perceived as disapproval and rejection;

- experiences severe psychological stress during assessment. During the exam may experience such intense excitement and anxiety that makes him/her feel disorganized;

- has a high degree of emotional disadaptation as symptoms of depression and anxiety;

- $\quad$ uses avoidant behavior in a stress situation. Inclined to postpone the task execution and solving of problems that arise in the course of learning activities. 
Social phobia is an extreme manifestation of social anxiousness. Social anxiousness brings discomfort and makes some situation painful and unpleasant, the social phobia leads to a serious maladjustment and often to renounce activities related to frightening situations. Social phobia as part of ICD10 has the status of an independent mental disorders, the criteria for its clinical diagnosis and, the standards of medical and psychotherapeutic treatment are developed. Studies show that this disorder is associated with the high risk of suicide and substance abuse. Typical symptoms of social phobia are severe anxiety, severe tension, redness of the face, lump in throat feeling, palpitations, dry mouth, nausea, tremor and weakness in the legs, the inability to concentrate in situations provoking fear[6].

The problem of social fears is actively developed by Russian and foreign researchers. But the problems of interrelationship between social anxiousness and psychological defense mechanisms remain open, which determined the background and the novelty of the study presented below.

The objective of our research (2010-2015) was to study the tensions of various kinds of psychological defense mechanisms among students with different levels of social anxiousness. This study was conducted as part of the comprehensive program of psychosocial support for students who find in conditions of disadaptation.

\section{EXPERIMENT EXPESSION}

The study included 168 students of TSPU of faculty of psychology, public affairs and advertising aged from 19 to 20 years.

In the course of the study the students were offered the test by M. Libovits in the modification of O. A. Sagalakova and D. V. Truevtsev and Plutchik-Kellerman-Conte questionnaire.

Statistical processing of the results was carried out using of Student's t-test and methods of correlation analysis (Spearman's rank correlation coefficient).

Using the rank scale of social anxiousness intensity (from 1 to 3) by M. Libovits, two groups of students were identified. One group of students $(n=91)$ had a low level of expression of social anxiousness (1.0-1.4), and the second group $(n=67)$ had an increased level of social anxiousness (1.5-2.0).

For evaluation of tension of various types of psychological defense mechanisms Plutchik-Kellerman Conte questionnaire consisting of 92 questions was used, in which 8 ego defense mechanisms form eight separate scales: repression, regression, displacement, denial, psychological projection, compensation, hypercompensation, rationalization. The evaluation of tension of various types of psychological defense mechanisms was calculated using the formula: ratio of the number of positive responses to a number of scale statements.
The identification and evaluation of correlation between psychological defense mechanisms in the groups with low and high levels of social anxiousness was carried out with the help of Spearman's rank correlation coefficient.

It was found that in the groups with low and high levels of social anxiousness the different structures of correlative relations are observed. In the first case only two statistically significant correlations are revealed: displacement and rationalization, rationalization and psychological projection. In the second case five correlations are revealed: repression and psychological projection, regression and displacement, compensation and regression, compensation and displacement, compensation and denial.

The indicators of tension of various types of psychological defense mechanisms expressed in percent (from 0 to 100\%) were subdivided into three groups according to the ranges of tension:

- $\quad$ the range of low tension $(0-40,0)$;

- $\quad$ the range of average tension $(41,0-64,0)$;

- the range of high tension (65,0-100).

The proportion of each type of psychological defense mechanisms in accordance with the ranges of tension in a group of students with a low and a high level of social anxiousness clearly presented in the table 1 and 2 .

TABLE I. THE PROPORTION OF EACH TYPE OF PSYCHOLOGICAL DEFENSE MECHANISMS IN ACCORDANCE WITH THE RANGES OF TENSION IN A GROUP OF STUDENTS WITH A LOW AND A HIGH LEVEL OF SOCIAL ANXIOUSNESS

\begin{tabular}{|c|c|c|c|c|c|c|c|c|}
\hline \multirow{2}{*}{$\begin{array}{c}\text { Ranges } \\
\text { of } \\
\text { tension } \\
\text { of } \\
\text { psycholo } \\
\text {-gical } \\
\text { defense } \\
\text { mecha- } \\
\text { nisms }\end{array}$} & \multicolumn{8}{|c|}{$\begin{array}{c}\text { Types of psychological defense mechanisms (expressed in } \\
\text { decimals) }\end{array}$} \\
\hline & 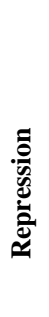 & 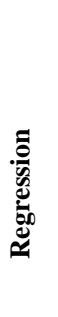 & 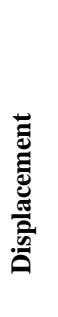 & 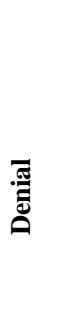 & 苞 & 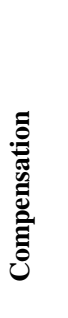 & 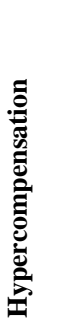 & 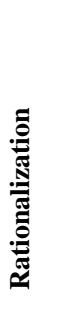 \\
\hline $0-40,0$ & 0.8 & 0.62 & 0.2 & 0.62 & 0.23 & 0.54 & 0.77 & 0.38 \\
\hline $41,0-65,0$ & 0.2 & 0.31 & 0.08 & 0.3 & 0.46 & 0.46 & 0.15 & 0.46 \\
\hline $65,0-100$ & 0 & 0.07 & 0 & 0.08 & 0.31 & 0 & 0.08 & 0.16 \\
\hline
\end{tabular}

Repression as psychological defense mechanism was used by majority of the respondents from the group with low level of social anxiousness $(0,8)$ in the range of low tension of psychological defense mechanism, and the minor part $(0,2)$ had the indicators of tension of the second level. In the group 
with high level of social anxiousness the ratio of the respondents with the low and average levels of psychological defense mechanisms tension was approximately $1: 1(0,55$ and 0,45 correspondingly).

TABLE II. THE PROPORTION OF EACH TYPE OF PSYCHOLOGICAL DEFENSE MECHANISMS IN ACCORDANCE WITH THE RANGES OF TENSION IN A GROUP OF STUDENTS WITH A HIGH LEVEL OF SOCIAL ANXIOUSNESS

\begin{tabular}{|c|c|c|c|c|c|c|c|c|}
\hline \multirow{2}{*}{$\begin{array}{c}\begin{array}{c}\text { Ranges } \\
\text { of }\end{array} \\
\text { tension } \\
\text { of } \\
\text { psycholo- } \\
\text { gical } \\
\text { defense } \\
\text { mecha- } \\
\text { nisms }\end{array}$} & \multicolumn{8}{|c|}{$\begin{array}{c}\text { Types of psychological defense mechanisms (expressed in } \\
\text { decimals) }\end{array}$} \\
\hline & 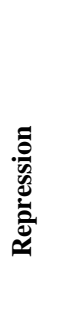 & 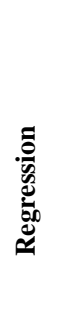 & 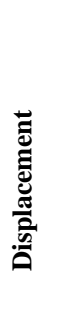 & 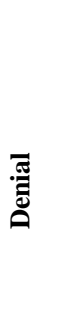 & 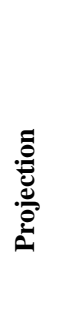 & 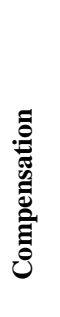 & 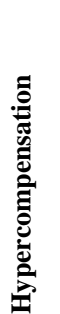 & 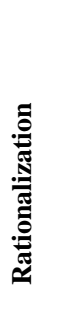 \\
\hline $0-40,0$ & 0.55 & 0.36 & 0.64 & 0.62 & 0.09 & 0.36 & 0.64 & 0.36 \\
\hline $41,0-65,0$ & 0.45 & 0.45 & 0.36 & 0.34 & 0.55 & 0.55 & 0.27 & 0.55 \\
\hline $65,0-100$ & 0 & 0.19 & 0 & 0.04 & 0.36 & 0.09 & 0.09 & 0.09 \\
\hline
\end{tabular}

Regression as psychological defense mechanism was used by respondents of both groups (with low and high level of social anxiousness), herewith, in the first group the respondents with low tension of psychological defense mechanisms $(0-41,0)$ are predominated $(0,62)$.

In the group with the high level of social anxiousness noticeably increased the part of respondents in the range of average tension $(0,45)$, which is the evidence of tension of this kind of psychological defense mechanisms.

'Denial' is characterized by shared distribution of respondents in each studied group according to the degree of tension of a given psychological defense mechanism.

Psychological projection is actively used by the respondents of both studied groups: with low and high levels of social anxiousness. What is more, in both groups there is quite large number of individuals who use this kind of psychological defense mechanism in the range of high tension. In the group with high level of social anxiousness the part of the respondents using the psychological defense of the second range of tension $(41,0-65,0)$ is higher, which indicates the tension of the psychological defense mechanism of given type.

Considering 'psychological projection' it may be noted the predominance of the number of individuals using the given psychological defense of second $(41,0-65,0)$ and third $(65,0$ 100) ranges in the group of students with the high level of social anxiousness. In the group of low level of social anxiousness the part of respondents, who use the given psychological defense in the low $(0-41,0)$ and average $(41,0$ $65,0)$ ranges of tension is prevalent.
Distribution of respondents of studied groups according to the ranges of 'hypercompensation' psychological defense tension shows a small predominance of the individuals with the tension of the second $(41,0-64,0)$ and the third $(65,0-100)$ ranges in the group with high level of social anxiousness.

'Rationalization' is characterized by large number of respondents using the given psychological defense mechanism of the second range $(41,0-64,0)$ in the group with high level of social anxiousness $(0,55)$. In general, the differences in this psychological defense mechanism are less noticeable.

Summing up results on a study of tension of psychological defense mechanisms and distribution of respondents to the groups of low and high level of social anxiousness in accordance with the distinguished ranges of tensions of psychological defense mechanisms, some points should be noted:

- $\quad$ in the group of students with low level of social anxiousness predominated the number of individuals with low tension of psychological defense mechanisms (of the first range 0-40,0);

- $\quad$ in the group of students with high level of social anxiousness predominated the number of individuals with average and high tension of psychological defense mechanisms.

Research data of average levels of each types of psychological defense mechanisms are presented in the Table 3 .

TABLE III. AVERAGE VALUES OF INDICATORS OF SOCIAL ANXIOUSNESS (2), AVOIDANCE (3) AND TENSION OF PSYCHOLOGICAL DEFENSE MECHANISMS (4-11) IN THE GROUPS WITH THE LOW AND HIGH LEVELS OF SOCIAL ANXIOUSNESS

\begin{tabular}{|c|c|c|c|c|c|c|c|c|c|c|}
\hline ڤ̆ & 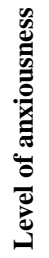 & 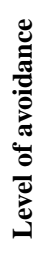 & 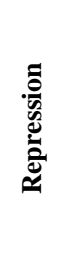 & 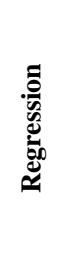 & 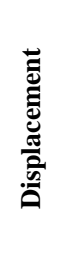 & & 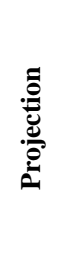 & 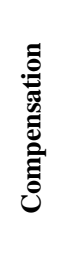 & 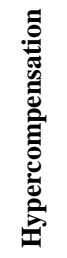 & 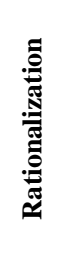 \\
\hline 1 & 2 & 3 & 4 & 5 & 6 & 7 & 8 & 9 & 10 & 11 \\
\hline I & 1.3 & 1.7 & 29.2 & 33.3 & 20.0 & 34.3 & 47.8 & 34.2 & 26.6 & 41.9 \\
\hline II & 1.7 & 1.8 & 34.5 & 42.6 & 33.6 & 33.7 & 53.0 & 53.6 & 38.2 & 41.6 \\
\hline
\end{tabular}

Analyzing the data of table 3 , we can say about the tendency towards increasing of rates of tension of various types of psychological defense mechanisms in a group with the high level of social anxiousness. For the indicators "regression", "displacement", "projection" and "compensation" statistically reliable differences (using of Student's t-test) with significance level of $\mathrm{p}<0.05$ were found. The wide range of values of one and the same type of 
psychological defense mechanisms within each studied group shows the individual characteristics of the use of a particular type of psychological defense mechanism, which also includes those one do not enlisted in the questionnaire as well as coping strategies and another types of psychological defense mechanisms (rituals, conditional actions, words).

In the group of students with the high level of social anxiousness the higher level of tension of certain types of psychological defense mechanisms compared to the group of low level of social anxiousness. It concerns the following types: regression, displacement, projection, compensation, hypercompensation.

Appeal to regression to protect against anxiety allows to express discontent, unconsciously create the elements of the child's behavior (crying, etc.), the weakness of the emotionalvolitional control (women, psychopathic personality, adolescent groups tend to the use of the given psychological defense mechanism.

Displacement is more intrinsic in a situation of failure of the social situation, such as the exam. Some individuals allow themselves to choose the less threatening (replacing) objects than the examiner, such as doors that can be slammed loudly. Displacement resolves the emotional tension, but mostly does not lead to achievement of this goal. The young age of the respondents can explain the use of this psychological defense mechanism.

When using projection, the student can put the blame for failure on the circumstances, the teacher or other students. Projection is usually aimed at objects, the real properties which may correspond to the projected characteristic.

The tension of "compensation" and "hypercompensation" indicates presence of the inner subjective inferiority complexes which can develop because of a feeling of psychological or social impotence. Hypercompensation or superiority complex is expressed in the tendency to exaggerate one's abilities (in this case) in social communication.

\section{CONCLUSION.}

To sum up, the students with increased level of social anxiousness use in critical situations both the less mature mechanisms (projective psychological defense mechanisms) such as repression and regression and the more mature such as psychological projection and compensation using perceptual defense levels with the removal of information from the consciousness as well as the level of restructuring of the information. The choice of psychological defense mechanisms depends on many factors and primarily on personality structure, level of educational attainment, social status, age and sex, which requires further study. A powerful stress or crisis factor, mental disorder or pharmacological deviations can determine the specific set of used psychological defense mechanisms.

Avoidance as the concurrent strategy was not associated with the indexes of anxiousness levels in selected groups and probably characterizes the usual style of behavior, which aims to eliminate the psychological threat of unpleasant situations. Tension of psychological defense mechanisms was increasing with anxiousness increase. However, the reasons for the selectional tension of psychological defense mechanisms and the interrelationship between them need to be further explored. In our studies the mechanisms of psychological defense were contributing to psychological adaptation of respondents to stressful situations, but many of them had inner conflicts in significant social situations were revealed, which meant real obstacles to self-realization.

\section{REFERENCES}

[1] Shelekhov I. L. The ideal image of female partners at modern students from different ethnic groups/ I. L. Shelekhov, E. V. Grebennikova, O.G. Berestneva // Fundamental research, no. 10 (Part 4), 2013. - P. 866-889. URL:

www.rae.ru/fs/?section=content\&op=show_article\&article_id=1000163 2 (reference date: 04.08.2014).

[2] Shelekhov I. L. Methods of active socio-psychological training: methodical complex / I. L. Shelekhov, E. V. Grebennikova, P. V. Ivanichko; FBGOI VPO «Tomsk State Pedagogical University» Tomsk: Publishing House of Tomsk State Pedagogical University, 2014. - 264 p. - ISBN 978-5-89428-729-4.

[3] Bulatova T. A. Social anxiety in the sphere of psychological protections / T. A. Bulatova, E. I. Chernykh // Tomsk State Pedagogical University Bulletin. 2010. ISS. 2 (92). - P. 107-112.

[4] Sagalakova O. A. Social fears and social phobia: monograph / O. A. Sagalakova, D. V. Truevtsev. - Tomsk: TSU Publishing House, 2007. 210 p.

[5] Krasnova V. V. Social anxiousness and student maladjustment / V. V. Krasnova, A. B. Kholmogorova // Psychological Science and Education. 2011. №1.

[6] Perret M. Clinical Psychology and Psychotherapy / M. Perret, W. Baumann. -St. Petersburg: Piter, 2012. - 944 p.

[7] Berestneva, O.G., Pekker J.S. Simulation and evaluation of biological systems adaptive capabilities // Proceedings of 2014 International Conference on Mechanical Engineering, Automation and Control Systems, MEACS 2014, 15 December 2014, Article number 6986860.

[8] Berestneva O.G., Marukhina O.V., Ivankina L.I., Shukharev S.O. Modelling of Adaptation Strategies for Different Entities // The European Proceedings of Social \& Behavioural Sciences (EpSBS). 2016. - Vol. 7 : Lifelong Wellbeing in the World (WELLSO 2015), pp. 252-258. 